\title{
Diagnóstico de impactos ambientais nas águas do trecho perenizado do rio Piancó-Piranhas-Açu, Paraíba, Brasil
}

A água é um dos recursos naturais essenciais para a sobrevivência dos seres vivos, além de contribuir para a manutenção dos ciclos naturais, especialmente 0 hidrológico. Entretanto, tal recurso é passivo de degradação pelas atividades antrópicas realizadas de maneiras inadequadas, assim, comprometendo a disponibilidade e quantidade desse recurso. Neste trabalho objetivou-se elaborar um diagnóstico dos impactos ambientais nas águas do Rio Piancó-Piranhas-Açu no trecho situado entre as cidades de Pombal - PB e Paulista - PB. A metodologia utilizada teve por base pesquisas bibliográficas em fontes científicas e técnicas, visitas a campo, fotodocumentação e consultas a órgãos públicos. Para tanto, fez-se o georreferenciamento da área a partir de ferramentas de geoprocessamento. Em seguida, foi realizada a catalogação das atividades antrópicas com potencial impactante e a identificação dos impactos ambientais nas águas do rio, por meio dos métodos de AIA: Ad Hoc, Check Lists e Matriz de Interação. Além disso, indicaram-se medidas de controle. De acordo com os resultados, foram identificados 52 impactos nas águas do rio, sendo que $43 \%$ "muito significativos", 36\% "significativos" e $21 \%$ "não significativos". Por fim, espera-se que os resultados obtidos neste estudo sirvam como base para estudos ambientais futuros nas águas do rio Piancó-Piranhas-Açu.

\section{Diagnosis of environmental impacts in the waters of the perenized section of the Piancó-Piranhas-Açu river, Paraíba, Brasil}

Water is one of the essential natural resources for the survival of living beings, in addition to contributing to the maintenance of natural cycles, especially hydrological. However, such a resource is liable to be degraded by human activities carried out in inappropriate ways, thus compromising the availability and quantity of this resource. This work aimed to elaborate a diagnosis of the environmental impacts in the waters of the Piancó-Piranhas-Açu River in the stretch located between the cities of Pombal - PB and Paulista - PB. The methodology used was based on bibliographic searches in scientific and technical sources, field visits, photocumentation and consultations with public agencies. Therefore, the area was georeferenced using geoprocessing tools. Then, the cataloging of anthropic activities with an impacting potential and the identification of environmental impacts in the river's waters were carried out, using the ElA methods: Ad Hoc, Check Lists and Interaction Matrix. In addition, control measures were indicated. According to the results, 52 impacts on the river's waters were identified, with $43 \%$ "very significant", $36 \%$ "significant" and $21 \%$ "not significant". Finally, it is expected that the results obtained in this study will serve as a basis for future environmental studies in the waters of the Piancó-Piranhas-Açu river.

Keywords: Environmental Impact Assessment; Environmental degradation; Environment.

José Ludemario da Silva Medeiros (iD) Universidade Estadual da Paraíba, Brasil http://lattes.cnpq.br/4084311510300833 http://orcid.org/0000-0002-7523-9601 joseludemariomedeiros@gmail.com

\section{luri Souza de Jesus}

Universidade Federal de Campina Grande, Brasil http://lattes.cnpq.br/9940532745543327 moixaiuri@gmail.com

Tássio Jordan Rodrigues Dantas da Silva Universidade Estadual da Paraíba, Brasil http://lattes.cnpq.br/1991160864996557 http://orcid.org/0000-0002-1708-5472 tassiojordan@hotmail.com
Maxsuel Bezerra do Nascimento (iD Universidade Estadual da Paraíba, Brasil http://lattes.cnpq.br/7100621157794567 http://orcid.org/0000-0001-6381-2688 maxsuel10gba@hotmail.com

Janaína Aparecida Cezário

Universidade Estadual da Paraíba, Brasil http://lattes.cnpq.br/2080075497375535 ja nayna2@yahoo.com.br

Jéssica Araújo Leite Martildes

Universidade Estadual da Paraíba, Brasil http://lattes.cnpq.br/4861712674645692 jessmartildes@gmail.com
José Cleidimário Araújo Leite

Universidade Federal de Campina Grande, Brasil http://lattes.cnpq.br/7938270564009075

cleidimario@yahoo.com.br

Laércio Leal dos santos (ic

Universidade Estadual da Paraíba, Brasil http://lattes.cnpq.br/6344196123061264 http://orcid.org/0000-0002-8175-4378 laercioeng@yahoo.com.br

\section{William de Paiva}

Universidade Estadual da Paraíba, Brasil http://lattes.cnpq.br/2612977983185686 http://orcid.org/0000-0003-0220-1247 w.paiva461@gmail.com

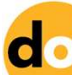

DOI: 10.6008/CBPC2179-6858.2021.005.0033

\section{Referencing this:}

MEDEIROS, J. L. S.; JESUS, I. S.; SILVA, T. J. R. D.; NASCIMENTO, M. B. CEZÁRIO, J. A.; MARTILDES, J. A. L.; LEITE, J. C.; SANTOS, L. L.; PAIVA, W.. Diagnóstico de impactos ambientais nas águas do trecho perenizado do rio Piancó-Piranhas-Açu, Paraíba, Brasil. Revista Ibero Americana de Ciências Ambientais, v.12, n.5, p.409-423, 2021. DOI: http://doi.org/10.6008/CBPC2179-6858.2021.005.0033 


\section{INTRODUÇÃO}

A água é um bem comum, indispensável para a sobrevivência dos seres vivos, e de fundamental importância para o desenvolvimento das atividades de ordem socioeconômica. Além de ser um dos recursos naturais essenciais para assegurar a vida no planeta Terra, é de extrema importância para garantir a manutenção dos ciclos hidrológicos e o equilíbrio das funções ambientais ou ecológicas (SOUZA et al., 2018). No âmbito global, o Brasil possui uma significante quantidade de água, estima-se que o País possua cerca de $12 \%$ da disponibilidade de água doce do planeta. Apesar da abundância, os recursos hídricos brasileiros não são inesgotáveis, além disso, o acesso à água não é igual para todos. Sendo assim, a região Norte, por exemplo, detém cerca de $80 \%$ da quantidade de água disponível, mas representa apenas $5 \%$ da população brasileira, por outro lado as regiões litorâneas do País possuem mais de $45 \%$ da população, porém, menos de $3 \%$ dos recursos hídricos (ANA, 2018).

No entanto, a disponibilidade desse recurso natural é influenciada por diversos fatores, tais, como, as características geográficas de cada região e as mudanças de vazão dos rios, que ocorrem devido às variações climáticas ao longo do ano, afetando a distribuição desse recurso, a exemplo da região semiárida do nordeste do Brasil (MMA, 2018). No Semiárido Brasileiro ocorre com certa frequência o processo natural denominado por "Seca", fenômeno natural que altera o regime hidrológico, afeta a população da região, principalmente os moradores mais vulneráveis, criando situações de deficiência hídrica e riscos para a segurança alimentar, energética e hídrica na região (EAKIN et al., 2014; MARENGO et al., 2016).

Na Bacia Hidrográfica do Rio Piancó-Piranhas-Açu (BHRPPA), situada na região semiárida brasileira, que abrange parte dos Estados da Paraíba e do Rio Grade do Norte (AESA, 2019), há diversos problemas relacionados à ação antrópica, sendo os principais, segundo o Comitê da Bacia Hidrográfica do Rio PiancóPiranhas-Açu (CBHPPA): contaminação das águas, assoreamento pelo uso inadequado do solo, degradação da mata ciliar, erosão generalizada e escassez hídrica (CBHPPA, 2019).

O principal rio da BHRPPA é o Piranhas, que nasce no município de Bonito de Santa Fé - PB e deságua no Oceano Atlântico, na Costa Potiguar (AESA, 2019). Este rio recebe as águas de dois grandes rios paraibanos: o Rio do Peixe e o Rio Piancó - considerado, por alguns pesquisadores, o principal rio da referida bacia - e é perenizado pelo Rio Piancó, a partir do Sistema Hídrico Curema-Mãe D’Água, até a barragem "Armando Ribeiro Gonçalves", no Estado do Rio Grande do Norte. Diante deste contexto, neste trabalho, propôs-se realizar a identificação dos impactos ambientais nas águas do Rio Piancó-Piranhas-Açu no trecho situado entre as cidades de Pombal e Paulista, localizadas na região do sertão do Estado da Paraíba.

\section{METODOLOGIA}

A área de estudo encontra-se situada no Oeste do Estado da Paraíba, na Região Geográfica Intermediária de Patos e na Região Geográfica Imediata de Pombal (IBGE, 2017), e abrange os municípios de Pombal e Paulista, sendo que, o Rio Piancó-Piranhas-Açu nasce no estado paraibano, e é perenizado pelo sistema hídrico Curema-Mãe D’Água, no município de Coremas (Figura 1). 


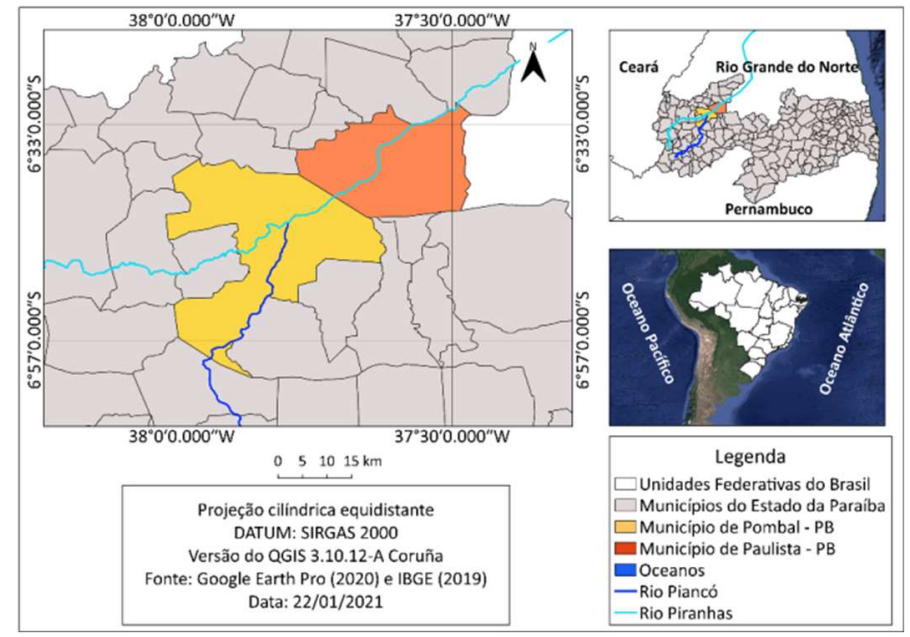

Figura 1: Localização da área de estudo.

A caracterização ambiental da área de estudo foi realizada por meio de visitas de campo, imagens de satélite, pesquisas bibliográficas e em estudos realizados na área da pesquisa. Na Tabela 1, estão apresentados os componentes ambientais que foram descritos na caracterização ambiental.

Tabela 1: Componentes que foram descritos na caracterização ambiental da área influência do estudo.

\begin{tabular}{ll}
\hline Meio & Componente ou fator ambiental \\
\hline \multirow{3}{*}{ Físico } & Clima \\
& Solos \\
& Recursos hídricos \\
\hline Biótico & Flora \\
\hline Antrópico & Fauna \\
\hline
\end{tabular}

A área de influência do estudo encontra-se no trecho perenizado do Rio Piancó-Piranhas-Açu, abrangendo os municípios de Pombal e Paulista entre as coordenadas geográficas de latitude, $\mathrm{S}$ $6^{\circ} 47^{\prime} 12,88^{\prime \prime}$ e $S 6^{\circ} 35^{\prime} 13,7^{\prime \prime}$, e longitude, W $37^{\circ} 48^{\prime} 54,74^{\prime \prime}$ e $W 37^{\circ} 37^{\prime} 12,4^{\prime \prime}$, respectivamente, possuindo aproximadamente $35,5 \mathrm{~km}$ de extensão. A área de influência desse estudo foi definida com base na área de mata ciliar no trecho do rio em questão, no que preconiza a Lei n. 12.651, de 25 de maio de 2012, que instituiu o "Novo Código Florestal Brasileiro" (BRASIL, 2012). Para tal, a área de estudo foi dividida em Área de Influência Direta (AID) e Área de Influência Indireta (AII). As referidas áreas foram definidas com base em critérios teóricos (conceituais/didáticos) e técnicos, conforme exposto na Tabela 2.

Tabela 2: Critérios adotados para a definição da área de influência do estudo

\begin{tabular}{ll}
\hline $\begin{array}{l}\text { Área de } \\
\text { influência' }\end{array}$ & Critérios \\
\hline AID & $\begin{array}{l}\text { Área onde ocorrem os impactos ambientais diretos, e parte dos indiretos, sobre as águas do rio, resultantes de } \\
\text { atividades antrópicas na área de influência e até próximas a esta área. }\end{array}$ \\
All & $\begin{array}{l}\text { Área onde estão situadas as atividades antrópicas que ocasionam impactos ambientais diretos e indiretos nas } \\
\text { águas do rio. }\end{array}$ \\
\hline
\end{tabular}

${ }^{\mathrm{TM}}$ somente serão avaliados os impactos ambientais para a AID, tendo em vista que o foco principal do trabalho foi o trecho perenizado do Rio Piancó-Piranhas-Açu situado entre os municípios de Pombal - PB e Paulista - PB. Fonte: ISMAEL (2016).

O georreferenciamento da área de influência foi realizado por meio da utilização de imagens do Google Earth Pro e de shapefiles, fornecidos pelo IBGE (2015), e do software Qgis (versão 2.14), a partir do 
qual foram construídos mapas da área de influência. A partir dos dados e informações obtidas em campo e das ferramentas utilizadas no estudo, foram construídos mapas georreferenciados da área de influência do trecho do rio, de uso e ocupação do solo e com indicação dos pontos mais impactados ao longo desse trecho do rio.

As atividades antrópicas com potenciais impactantes na área do estudo foram obtidas a partir de visitas a campo, fotodocumentação e complementadas por consultas a órgãos públicos, a exemplo das secretarias das prefeituras dos municípios em questão, Agência Executiva de Gestão das Águas no Estado da Paraíba (AESA), da Agência Nacional das Águas (ANA) e do Instituto Brasileiro de Geografia e Estatística (IBGE).

A identificação dos aspectos e impactos ambientais nas águas do Rio Piancó-Piranhas-Açu, foi realizada por meio dos dados e informações encontradas no levantamento sobre as atividades humanas e da utilização dos métodos de Avaliação de Impactos Ambientais (AIA). Para isso, foram utilizados os seguintes métodos de AIA: Ad Hoc (Método Espontâneo) e Check Lists (Listagens de Controle) de acordo com Fogliatti et al. (2004); Sánchez (2008); Cunha et al. (2010).

A seleção dos impactos ambientais significativos foi realizada a partir do grau de sua significância, em "muito significativo", "significativo" e "não significativo", definindo-se a magnitude e importância do impacto. A magnitude de um impacto corresponde a sua intensidade. Segundo o Departamento Nacional de Infraestrutura de Transporte (DNIT), a magnitude refere-se ao grau de incidência de um impacto sobre um determinado fator ambiental. Ela pode ser classificada como "grande, média ou pequena" (DNIT, 2009).

A importância do impacto diz respeito à necessidade de mitigar o efeito negativo do impacto ambiental, propondo medidas de controle ambiental. De acordo com DNIT (2009), a importância refere-se ao grau de interferência do impacto ambiental sobre diferentes componentes ambientais e está associada com a importância da perda, e pode ser também classificada como "grande, média ou pequena". Na tabela 3, estão apresentadas as informações sobre as definições para a classificação da "magnitude" e “importância”.

Tabela 3: Descrição da classificação quanto à magnitude e importância.

\begin{tabular}{|c|c|c|}
\hline Critério & Classificação & Descrição \\
\hline \multirow{3}{*}{ Magnitude } & Baixa/pequena & Quando a intensidade da alteração é baixa para o elemento ambiental. \\
\hline & Média & Quando a intensidade da alteração é média para o elemento ambiental. \\
\hline & Alta/grande & Quando a intensidade da alteração é alta para o fator ambiental. \\
\hline \multirow{3}{*}{ Importância } & Baixa/pequena & Quando o efeito negativo sobre o conjunto de elementos ambientais do local é baixo. \\
\hline & Média & Quando o efeito negativo sobre o conjunto de elementos ambientais do local é médio. \\
\hline & Alta/grande & Quando o efeito negativo sobre o conjunto de elementos ambientais do local é alto. \\
\hline
\end{tabular}

Fonte: Sá (2016).

Para a determinação da magnitude e importância dos impactos ambientais, a metodologia adotada foi a de Martildes et al. (2020), em que foi estabelecida uma escala de valores inteiros variando de 1 (um) a 10 (dez), em que estes valores correspondem a pesos atribuídos para cada impacto, de acordo com os critérios de referência e com base no entendimento dos conceitos de magnitude e importância, conforme exposto na Tabela 4.

Após o estabelecimento dos valores para magnitude, como para importância, foi realizada a 
multiplicação de ambos os valores, e o produto dessa operação foi enquadrado na classificação definida para o grau de significância dos impactos a partir de uma escala de significância variando de 1 (um) a 100 (cem), conforme exposto na Tabela 5.

Tabela 4: Escala para definição quanto à magnitude e importância.

\begin{tabular}{ll}
\hline Magnitude e importância & Escala individual \\
\hline Grande/alta & ] $7-10]$ \\
Média & ] $4-7]$ \\
Pequena/baixa & {$[1-4]$} \\
\hline
\end{tabular}

Fonte: Martildes et al. (2020).

Tabela 5: Escala para o grau de significância dos impactos ambientais

\begin{tabular}{ll}
\hline Significância & Escala \\
\hline Muito significativo - MS & ] $70-100]$ \\
Significativo - S & ] $40-70]$ \\
Não significativo - NS & {$[1-40]$} \\
\hline
\end{tabular}

Fonte: Martildes et al. (2020)

Após a seleção dos impactos quanto ao grau de significância, realizou-se a classificação dos impactos com base em procedimentos metodológicos encontrados na literatura técnica, em estudos de impacto ambiental e relatórios de impacto ambiental (EIAs/RIMAs), e científica apresentada em Fogliatti et al. (2004), Philippi et al. (2004) e Sánchez (2008), conforme exposto na Tabela 6.

Tabela 6: Metodologia de classificação dos impactos ambientais.

\begin{tabular}{|c|c|c|}
\hline Critério & Classificação & Fonte bibliográfica \\
\hline Quanto ao valor & $\begin{array}{l}\text { - Benéfico } \\
\text { - Adverso }\end{array}$ & Philippi et al. (2004) \\
\hline Quanto ao espaço de ocorrência & $\begin{array}{l}\text { - Local } \\
\text { - Regional } \\
\text { - Estratégico }\end{array}$ & \multirow[t]{2}{*}{ Fogliatti et al. (2004b) } \\
\hline Quanto ao tempo de ocorrência & $\begin{array}{l}\text { - Imediato, de médio ou longo prazo } \\
\text { - Permanente } \\
\text { - Cíclico }\end{array}$ & \\
\hline & - Temporário & Philippi et al. (2004) \\
\hline Quanto à reversibilidade & $\begin{array}{l}\text { - Reversível } \\
\text { - Irreversível }\end{array}$ & \multirow[t]{2}{*}{ Fogliatti et al. (2004b) } \\
\hline Quanto à chance de ocorrência & $\begin{array}{l}\text { - Determinístico } \\
\text { - Probabilístico }\end{array}$ & \\
\hline Quanto à incidência & $\begin{array}{l}\text { - Direto } \\
\text { - Indireto }\end{array}$ & Philippi et al. (2004) \\
\hline Quanto ao potencial de mitigação & $\begin{array}{l}\text { - Mitigável } \\
\text { - Não mitigável }\end{array}$ & Sánchez (2008b) \\
\hline
\end{tabular}

Fonte: Adaptado de Fogliatti et al. (2004b); Philippi et al. (2004); e Sánchez (2008b).

As medidas de controle ambiental foram propostas para os impactos ambientais "significativos" e "muito significativos" identificados, com a finalidade de prevenir, reduzir/mitigar ou compensar os impactos adversos. As medidas propostas nesse estudo foram realizadas com base em pesquisas na literatura e em estudo técnicos (EIA's/RIMA's) em áreas semelhantes.

\section{RESULTADOS E DISCUSSÃO}

Segundo Francisco et al. (2015) o clima dos municípios de Pombal e Paulista é do tipo Bsh (Semiárido quente) nas áreas mais baixas $(<300 \mathrm{~m})$ e AW' (Tropical quente e úmido com chuvas de verão- 
outono) nas áreas mais altas do terreno.

Em relação ao tipo de solo, cabe ressaltar que os municípios da área estudo estão inseridos na RGP, e segundo Francisco et al. (2015), a classe de solo predominante nessa localidade é do tipo Luvissolo Crômico com delimitações de Neossolos litólicos e algumas pequenas porções de outros solos. Além disso, o relevo dominante da área classificasse como suave ondulado a ondulado (FRANCISCO et al., 2015).

Os municípios de Pombal e Paulista estão inseridos na sub-região do baixo sertão paraibano, formada pela depressão do Rio Piancó-Piranhas-Açu e seus contribuintes. O referido rio nasce na Serra de Piancó no estado da Paraíba e deságua próximo à cidade de Macau no Rio Grande do Norte. Vale ressaltar, que é um rio intermitente em condições naturais como a maioria absoluta dos rios da região do semiárido nordestino, à exceção do rio São Francisco e do Parnaíba. Cabe frisar, que a perenidade de seu fluxo é assegurada por dois reservatórios de regularização construídos pelo DNOCS: O Curema - Mãe d'Água, na Paraíba, e a barragem Armando Ribeiro Gonçalves (ARG), no Rio Grande do Norte (CBHRPPA, 2021).

Segundo a Companhia de Pesquisa de Recursos Minerais (CPRM), o município de Pombal há a predominância de vegetação do tipo Caatinga Hiperxerófila com trechos de Floresta Caducifólia (CPRM, 2005a). Já no que tange o município de Paulista, a cobertura vegetal predominante é do tipo Caatingasertão (CPRM, 2005).

Em relação à fauna na área de influência do estudo, observou-se uma diversidade da fauna local, entre espécies "silvestres" e "domesticadas", e as principais espécies identificadas, foram: Carcará (Caracara plancus), Rolinha da caatinga (Columbina picui strepitans), Anum preto (Crotophaga ani), Coruja (Glaucidium brasilianum), porco (Sus scrofa domesticus), Galinha (Gallus gallus domesticus), Galinhad'angola ou Guiné ou capote (Numida meleagris) e Touro (Bos taurus). De acordo com o censo demográfico do IBGE realizado em 2010, a população estimada para os municípios de Pombal e Paulista no ano de 2020 foi aproximadamente 32.802 e 12.379 habitantes, além disso, o esgotamento sanitário adequado atinge $77,6 \%$ e $33,6 \%$ da população, respectivamente, de cada município da área de estudo (IBGE, 2010).

A atividade econômica predominante na maior parte do território dos dois municípios é a agropecuária. Sendo que as atividades pecuárias que são mais desenvolvidas nos dois municípios são, respectivamente: Bovina, ovina e galinácea (IBGE, 2010). A definição da área de influência é de suma importância para o desenvolvimento de qualquer tipo de estudo ambiental, pois, refere-se à área onde serão sentidos os efeitos dos impactos positivos e negativos do empreendimento (CARVALHO et al., 2019).

O Inciso III do artigo 5o da resolução do Conselho Nacional de Meio Ambiente (CONAMA) n. 001/86 estabelece a seguinte diretriz na elaboração de EIA/RIMA: “Definir os limites da área geográfica a ser direta ou indiretamente afetada pelos impactos, denominada área de influência do projeto, considerando, em todos os casos, a bacia hidrográfica na qual se localiza" (CONAMA, 1986). Diante disso, as informações sobre a definição da área de influência do estudo encontram-se na Tabela 7.

O georreferenciamento da área de influência de um empreendimento compreende a extensão geográfica a ser afetada direta e indiretamente pelos impactos gerados nas fases de planejamento, implantação, operação e desativação (quando for o caso) do mesmo, definindo a bacia hidrográfica como 
uma fundamental unidade territorial da avaliação ambiental (CAVALHO et al., 2019). Diante disso, as áreas de influência do estudo, AID e All encontram-se apresentadas na Figura 2.

Tabela 7: Critérios adotados para a definição da área de influência do estudo.

\begin{tabular}{ll}
\hline $\begin{array}{l}\text { Área de } \\
\text { influência }\end{array}$ & Critérios para definição da área \\
\hline AID & $\begin{array}{l}\text { Área de entorno do leito do rio Piancó (100 } \mathrm{m} \text { a partir de cada margem/borda do rio e incluindo-se a sua própria } \\
\text { área ao longo da extensão do trecho em estudo), situada entre as cidades de Pombal - PB e Paulista - PB. }\end{array}$ \\
\hline All & $\begin{array}{l}\text { Área de entorno do leito do rio Piancó ( } 300 \mathrm{~m} \text { a partir de cada borda da calha do leito regular, ao longo do trecho } \\
\text { perenizado, excetuando-se a AID), incluindo as áreas urbanas dos municípios de Pombal - PB e Paulista - PB }\end{array}$ \\
\hline AIT & Área de Influência Total, que corresponde à soma da AID e All. \\
\hline
\end{tabular}

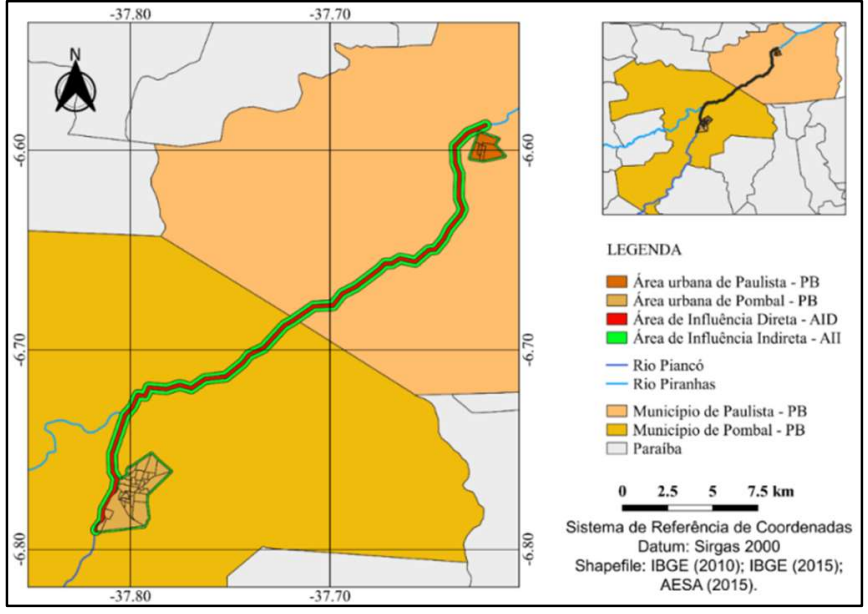

Figura 2: Mapa de localização da área de influência do estudo

A partir das informações coletadas nas visitas na área da pesquisa, foram constatados 8 tipos de atividades antrópicas com potencial impactante na área de influência do estudo. Vale ressaltar que não foi possível adentrar em todas as propriedades, devido às mesmas encontrarem-se fechadas, porém, as visitadas foram suficientes para obtenção das informações necessárias à confecção desse estudo. Diante disso, no Quadro 1 estão expostas as principais atividades antrópicas com potencial impactante identificada na área de estudo.

Quadro 1: Principais atividades com potencial impactante na área de influência do estudo Agricultura (sequeiro e irrigada)

Avicultura em pequena escala

Pecuária extensiva (Bovina, ovina e caprina)

Atividade / Suinocultura

empreendimento

Capitação d'água (consumo humano e entre outros usos)

Desmatamento da mata ciliar e outras áreas

Queijaria

Urbanização (expansão das cidades, geração de resíduos sólidos e lançamentos de efluentes)

Por meio do Quadro 1, verifica-se que a atividade mais desenvolvida na área de estudo é a agropecuária, sendo ela subdividida em diversas modalidades, destacando-se a pecuária no modelo extensivo, agricultura e a urbanização. Na Figura 3, estão apresentadas as informações em síntese das principais atividades com potencial impactante da área de estudo, em termos percentuais, destacando-se 8 atividades. Por meio da Figura 3, observa-se que a atividade predominante é a pecuária extensiva (Bovina, Ovina e Caprina), com cerca de $35 \%$ do total das atividades verificadas, seguida pela avicultura (pequena escala) e agricultura, com cerca de $20 \%$ e $17 \%$, respectivamente. 
- Agricultura

(Sequeiro e irrigada)

Avicultura em pequena escala

\section{= Pecuária \\ extensiva \\ (Bovina, ovina e \\ caprina)}

Figura 3: Percentuais de desenvolvimento das principais atividades com potencial impactante identificadas na área de estudo

Ismael et al. (2019) realizou um estudo semelhante, no qual foi realizado a avaliação dos impactos ambientais nas águas do Rio Piancó no trecho entres as cidades de Coremas a Pombal, verificou-se que a atividade antrópica predominante às margens do referido rio foi a agricultura, representando $27,9 \%$ dos tipos de atividades identificadas, seguida pela pecuária extensiva, com 19,7\%. Com base nesse contexto, verifica-se que as atividades humanas mais desenvolvidas ao longo de todos os trechos perenizados do rio Piancó-Piranhas-Açu é a agricultura e pecuária.

A partir das visitas na área do estudo, verificaram-se 4 tipos de aspectos ambientais, ocasionando 12 tipos de impactos, que se traduzem em um total de 52 impactos ambientais nas águas do trecho perenizado do Rio Piancó-Piranhas-Açu, considerando que alguns tipos de impactos ocorrem de forma repetida em cada atividade/empreendimento na área de estudo, conforme o Quadro 2. Diante disso, na pesquisa realizada no município de Mossoró - RN, por Filho; Guimarães et al. (2017), na Área de Relevante Interesse Ecológico (ARIE) da Ilha da Coroa, foram identificados 14 tipos de atividades impactantes e 145 impactos ambientais potenciais na localidade.

Tal realizada de degradação das APP's está presente em todas as regiões do Brasil. Perante isso, Silva et al. (2018) realizaram a identificação dos impactos ambientais em uma APP de morro com alta declividade no munícipio de Famoso do Araguaia, no Estado do Tocantins. Dentre os impactos identificados, destaca-se a exposição do solo ocasionada pelo desmatamento irregular, afugentamento da fauna local, compactação da camada superficial do solo pelo pisoteio dos rebanhos de gado bovino, erosão acelerada e assoreamento dos corpos hídricos. Segundo Cunha (2008), a expansão da agropecuária no território nacional está acontecendo de maneira muito agressiva ao meio ambiente, mediante a destruição da vegetação nativa, incluindo as APPs dos corpos d'água, juntamente com o uso inadequado de agroquímicos (agrotóxicos, fertilizantes, corretivos etc.), contribuindo assim, para o processo de degradação ambiental.

A destruição da vegetação nativa, principalmente a mata ciliar dos corpos d'água, vem contribuindo para a poluição e contaminação das águas, pois as matas ciliares são fundamentais para a proteção dos recursos hídricos. Além disso, esse processo pode comprometer a quantidade de água disponível e a qualidade de água potável (FERREIRA, 2016). 
Diagnóstico de impactos ambientais nas águas do trecho perenizado do rio Piancó-Piranhas-Açu, Paraíba, Brasil MEDEIROS, J. L. S.; JESUS, I. S.; SILVA, T. J. R. D.; NASCIMENTO, M. B.; CEZÁRIO, J. A.; MARTILDES, J. A. L.; LEITE, J. C.; SANTOS, L. L.; PAIVA, W.

Quadro 21: Aspectos e impactos ambientais identificados nas águas do Rio Piancó-Piranhas-Açu.

\begin{tabular}{|c|c|c|}
\hline Atividade/empreendimento & Aspectos ambientais & Impactos ambientais \\
\hline \multirow{7}{*}{ Agricultura de sequeiro de subsistência } & \multirow{3}{*}{ Retirada da mata ciliar } & Assoreamento de corpos de água \\
\hline & & $\begin{array}{l}\text { Eutrofização das águas dos corpos } \\
\text { hídricos superficiais }\end{array}$ \\
\hline & & $\begin{array}{l}\text { Alteração e degradação dos ambientes } \\
\text { aquáticos }\end{array}$ \\
\hline & Utilização/consumo de água & $\begin{array}{l}\text { Redução na disponibilidade dos recursos } \\
\text { hídricos }\end{array}$ \\
\hline & \multirow{2}{*}{$\begin{array}{l}\text { Lançamento de resíduos sólidos e/ou líquidos (ricos em matéria orgânica e/ou } \\
\text { nutrientes) }\end{array}$} & Poluição hídrica \\
\hline & & Contaminação hídrica \\
\hline & Utilização de agroquímicos & Mortandade de organismos aquáticos \\
\hline \multirow{4}{*}{$\begin{array}{l}\text { Avicultura em grande escala } \\
\text { (Comercialização) }\end{array}$} & \multirow{4}{*}{$\begin{array}{l}\text { Lançamento inadequado de resíduos sólidos e/ou líquidos (ricos em matéria } \\
\text { orgânica e/ou nutrientes) }\end{array}$} & Poluição hídrica \\
\hline & & Contaminação hídrica \\
\hline & & $\begin{array}{l}\text { Eutrofização das águas dos corpos } \\
\text { hídricos superficiais }\end{array}$ \\
\hline & & $\begin{array}{l}\text { Alteração e degradação dos ambientes } \\
\text { aquáticos }\end{array}$ \\
\hline \multirow{9}{*}{$\begin{array}{l}\text { Pecuária extensiva (Bovina, Ovina, } \\
\text { Caprina) }\end{array}$} & \multirow{2}{*}{ Retira da mata ciliar e outras áreas } & Alteração do fluxo hídrico \\
\hline & & Assoreamento de corpos de água \\
\hline & \multirow{6}{*}{$\begin{array}{l}\text { Lançamento inadequado de resíduos sólidos e/ou líquidos (ricos em matéria } \\
\text { orgânica e/ou nutrientes) }\end{array}$} & Poluição hídrica \\
\hline & & Contaminação hídrica \\
\hline & & Aumento na turbidez da água do Rio \\
\hline & & $\begin{array}{l}\text { Eutrofização das águas dos corpos } \\
\text { hídricos superficiais }\end{array}$ \\
\hline & & $\begin{array}{l}\text { Alteração e degradação dos ambientes } \\
\text { aquáticos }\end{array}$ \\
\hline & & Alteração da paisagem natural do rio \\
\hline & Utilização de agroquímicos de maneira inadequada & Mortandade de organismos aquáticos \\
\hline \multirow{8}{*}{ Suinocultura } & \multirow{8}{*}{$\begin{array}{l}\text { Lançamento de resíduos sólidos e/ou líquidos (ricos em matéria orgânica e/ou } \\
\text { nutrientes) }\end{array}$} & Poluição hídrica \\
\hline & & Contaminação hídrica \\
\hline & & Aumento da turbidez da água do rio \\
\hline & & Eutrofização do rio \\
\hline & & Aumento de odores desagradáveis \\
\hline & & Alteração da paisagem natural do rio \\
\hline & & $\begin{array}{l}\text { Alteração e degradação dos ambientes } \\
\text { aquáticos }\end{array}$ \\
\hline & & Mortandade de organismos aquáticos \\
\hline \multirow[b]{2}{*}{ Capitação d'água } & \multirow[b]{2}{*}{ Utilização/consumo da água } & Alteração do fluxo hídrico \\
\hline & & $\begin{array}{l}\text { Redução na disponibilidade de água nos } \\
\text { corpos hídricos }\end{array}$ \\
\hline \multirow{7}{*}{$\begin{array}{l}\text { Desmatamento da mata ciliar e outras } \\
\text { áreas }\end{array}$} & \multirow{7}{*}{ Retirada da mata ciliar/solo exposto } & Assoreamento de corpos de água \\
\hline & & Poluição hídrica \\
\hline & & Contaminação hídrica \\
\hline & & Alteração na qualidade das águas do rio \\
\hline & & $\begin{array}{l}\text { Alteração e degradação dos ambientes } \\
\text { aquáticos }\end{array}$ \\
\hline & & Mortandade de organismos aquáticos \\
\hline & & Alteração da paisagem natural do rio \\
\hline \multirow{5}{*}{ Queijaria } & \multirow{5}{*}{$\begin{array}{l}\text { Lançamentos de resíduos sólidos e/ou líquidos de maneira inadequada (ricos em } \\
\text { matéria orgânica e/ou nutrientes) }\end{array}$} & Poluição hídrica \\
\hline & & Contaminação hídrica \\
\hline & & Eutrofização do rio \\
\hline & & $\begin{array}{l}\text { Alteração e degradação dos ambientes } \\
\text { aquáticos }\end{array}$ \\
\hline & & Mortandade de organismos aquáticos \\
\hline \multirow{11}{*}{ Urbanização } & \multirow{2}{*}{ Retirada da mata ciliar/solo exposto } & Alteração do fluxo hídrico \\
\hline & & Assoreamento de corpos de água \\
\hline & \multirow{5}{*}{$\begin{array}{l}\text { Lançamentos de resíduos sólidos e/ou líquidos de maneira inadequada (ricos em } \\
\text { matéria orgânica e/ou nutrientes) }\end{array}$} & Poluição hídrica \\
\hline & & Contaminação hídrica \\
\hline & & Eutrofização das águas do rio \\
\hline & & $\begin{array}{l}\text { Alteração e degradação dos ambientes } \\
\text { aquáticos }\end{array}$ \\
\hline & & Mortandade de organismos aquáticos \\
\hline & \multirow{4}{*}{ Utilização/consumo de água } & $\begin{array}{l}\text { Aumento no volume demandado de } \\
\text { água }\end{array}$ \\
\hline & & Redução na disponibilidade de água \\
\hline & & Aumento no desperdiço de água \\
\hline & & Risco de escassez hídrica \\
\hline
\end{tabular}

No Quadro 2, verifica-se que todas as atividades antrópicas catalogadas nas margens do Rio PiancóPiranhas-Açu possuem grande potencial impactante, podendo ocasionar diversos impactos ambientais. Dentre os impactos identificados nas águas do rio, destacam-se: a poluição e contaminação hídrica, a eutrofização, o aumento da turbidez e a alteração na qualidade da água, que foram ocasionados com maior frequência pelas atividades antrópicas verificadas. Parte destes impactos foram também identificados por Ramos et al. (2020) que, ao avaliarem os impactos ambientais sob o Rio Espinharas, no município de Patos, 
destacaram o crescimento populacional como um fator que potencializa a propagação dos impactos ambientais identificados.

De acordo com Azevedo et al. (2015), ao longo de todo o percurso do Rio Piancó a vegetação ripária apresenta-se na maior parte degradada e com as suas águas eutrofizadas, conforme ilustrada na Figura 4. Diante disso, segundo Pinto et al. (2020), a eutrofização é um problema ambiental que afeta os ecossistemas de água doce por todo o mundo, como lagos e rios. Este processo provém do enriquecimento em nutrientes no meio aquático (principalmente compostos de Nitrogênio e Fósforo), que resulta essencialmente de lixiviados de solos agrícolas, descargas urbanas e industriais ou da criação de gado.

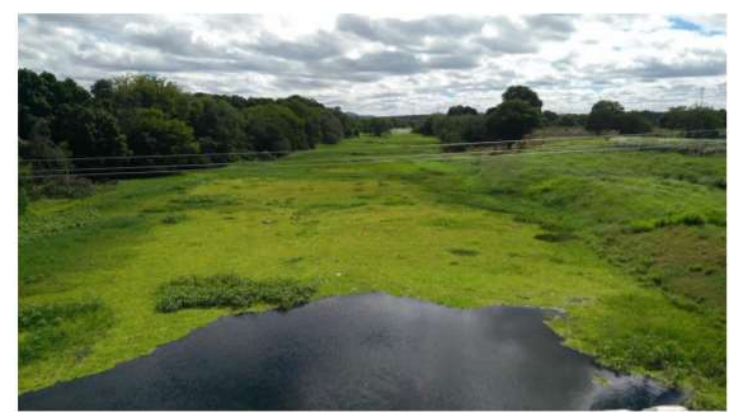

Figura 4: Presença de vegetação aquática cobrindo grande extensão do Rio Piancó.

Fonte: Junior et al. (2017)

No Quadro 3, apresenta-se uma matriz de interação que relaciona as atividades ou empreendimento com os impactos ambientais identificados na área de influência do estudo, na qual se fez a identificação e seleção dos impactos significativos e consequentemente dos não significativos, ocorrentes ou potenciais, nas águas do Rio Piancó-Piranhas-Açu.

Quadro 3 - Matriz de interação com a identificação dos impactos ambientais com significância na área de estudo

\begin{tabular}{|c|c|c|c|c|c|}
\hline \multirow[b]{2}{*}{ Atividade/empreendimento } & \multirow[b]{2}{*}{ Impactos ambientais } & \multicolumn{2}{|c|}{ Pesos } & \multirow{2}{*}{$\begin{array}{l}\text { Cálculo do } \\
\text { índice } \\
\text { Magnitude } \\
\text { X } \\
\text { Importância }\end{array}$} & \multirow{2}{*}{$\begin{array}{l}\text { Significância } \\
\text { MS / S / NS }\end{array}$} \\
\hline & & 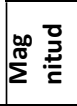 & 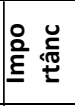 & & \\
\hline \multirow{7}{*}{ Agricultura (Sequeiro e irrigada) } & Assoreamento de corpos de água & 6 & 6 & 36 & NS \\
\hline & $\begin{array}{l}\text { Eutrofização das águas dos corpos hídricos } \\
\text { superficiais }\end{array}$ & 6 & 7 & 42 & $\mathrm{~S}$ \\
\hline & Alteração e degradação dos ambientes aquáticos & 7 & 8 & 56 & $\mathrm{~S}$ \\
\hline & Redução na disponibilidade dos recursos hídricos & 7 & 8 & 56 & $\mathrm{~S}$ \\
\hline & Poluição hídrica & 7 & 8 & 56 & $\mathrm{~S}$ \\
\hline & Contaminação hídrica & 7 & 8 & 56 & $\mathrm{~S}$ \\
\hline & Mortandade de organismos aquáticos & 7 & 8 & 56 & $\mathrm{~S}$ \\
\hline \multirow{4}{*}{$\begin{array}{l}\text { Avicultura em pequena escala } \\
\text { (consumo de subsistência) }\end{array}$} & Poluição hídrica & 4 & 5 & 20 & NS \\
\hline & Contaminação hídrica & 4 & 5 & 20 & NS \\
\hline & $\begin{array}{l}\text { Eutrofização das águas dos corpos hídricos } \\
\text { superficiais }\end{array}$ & 5 & 6 & 30 & NS \\
\hline & Alteração e degradação dos ambientes aquáticos & 5 & 5 & 25 & NS \\
\hline \multirow{9}{*}{ Pecuária bovina extensiva } & Alteração do fluxo hídrico & 7 & 7 & 49 & $\mathrm{~S}$ \\
\hline & Assoreamento de corpos de água & 9 & 10 & 90 & MS \\
\hline & Poluição hídrica & 7 & 8 & 56 & $\mathrm{~S}$ \\
\hline & Contaminação hídrica & 8 & 9 & 72 & MS \\
\hline & Aumento na turbidez da água do Rio & 7 & 7 & 49 & $\mathrm{~S}$ \\
\hline & $\begin{array}{l}\text { Eutrofização das águas dos corpos hídricos } \\
\text { superficiais }\end{array}$ & 8 & 9 & 72 & MS \\
\hline & Alteração e degradação dos ambientes aquáticos & 8 & 9 & 72 & MS \\
\hline & Alteração da paisagem natural do rio & 8 & 9 & 72 & MS \\
\hline & Mortandade de organismos aquáticos & 5 & 7 & 35 & NS \\
\hline \multirow{3}{*}{ Suinocultura } & Poluição hídrica & 7 & 7 & 49 & $\mathrm{~S}$ \\
\hline & Contaminação hídrica & 8 & 9 & 72 & MS \\
\hline & Aumento da turbidez da água do rio & 6 & 7 & 42 & $\mathrm{~S}$ \\
\hline
\end{tabular}


Diagnóstico de impactos ambientais nas águas do trecho perenizado do rio Piancó-Piranhas-Açu, Paraíba, Brasil

MEDEIROS, J. L. S.; JESUS, I. S.; SILVA, T. J. R. D.; NASCIMENTO, M. B.; CEZÁRIO, J. A.; MARTILDES, J. A. L.; LEITE, J. C.; SANTOS, L. L.; PAIVA, W.

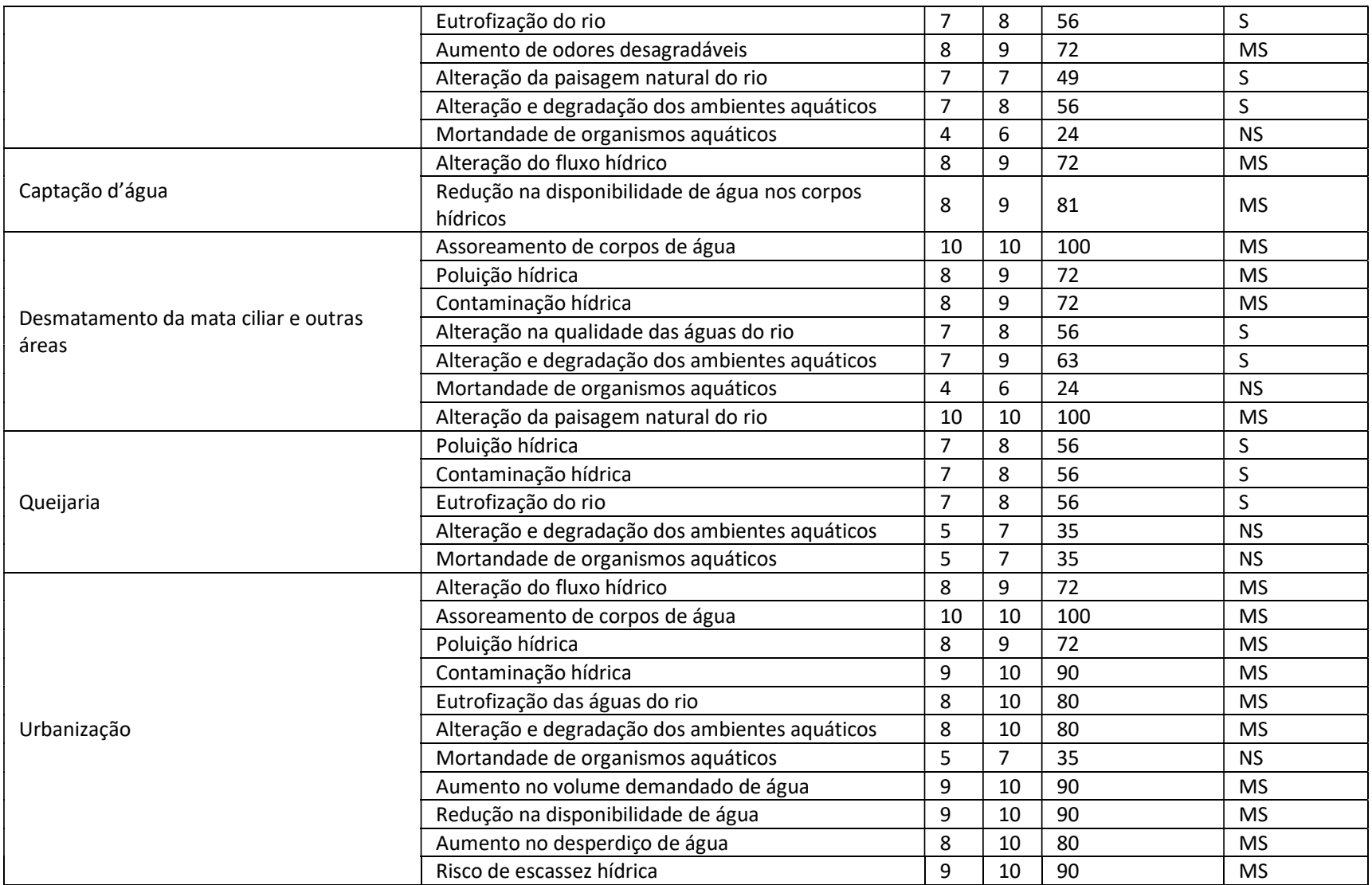

Legenda: (NS) Não Significativo; (S) Significativo e (MS) Muito Significativo.

Na Figura 5, estão apresentados os resultados da identificação dos impactos ambientais, de acordo com o grau de significância, em termos percentuais.

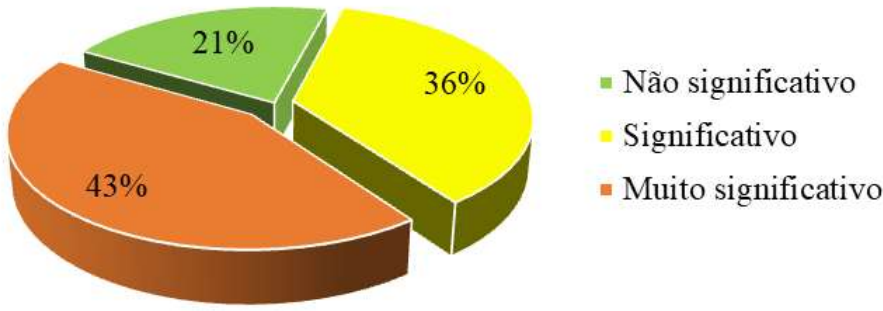

Figura 5: Grau de significância dos impactos na área de influência do estudo

Por meio da Figura 5, observa-se que entre os impactos "muito significativos" e "significativos" tem-se que os impactos com significância são 79\%. Na Figura 6, estão expostos em termos percentuais os impactos ambientais "muito significativos" relacionados às principais atividades/empreendimentos da área de estudo.

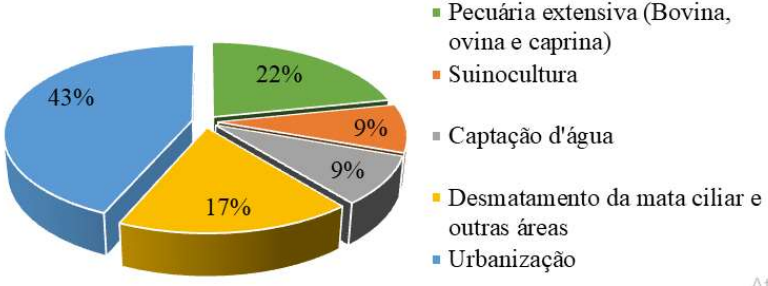

Figura 6: Impactos ambientais "muito significativos" relacionados às principais atividades/empreendimentos. 
Com base nas informações expostas na Figura 6, observa-se que as atividades/empreendimentos com o maior número de impactos ambientais "muito significativos" foram a urbanização, com $43 \%$ dos impactos identificados, seguida da pecuária extensiva (Bovina, ovina e caprina) e desmatamento da mata ciliar e outras áreas, com $22 \%$ e $17 \%$, respectivamente. Vale ressaltar que, apesar de a pecuária ter sido a atividade mais ocorrente na área de influência do estudo, conforme visto na Figura 3, a atividade que mais acarreta impactos ambientais "muito significativos" é a urbanização. No Quadro 4, apresenta-se a classificação dos impactos ambientais "significativos" e "muito significativos" identificados na área de influência do estudo.

Quadro 4: Classificação dos impactos "significativos" e "muito significativos" da área de influência do estudo

\begin{tabular}{|c|c|c|c|c|c|c|c|c|c|c|}
\hline Atividade /empreendimento & Impactos ambientais & & $\frac{\frac{0}{\pi}}{\frac{10}{3}}$ & & 量 & 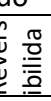 & & & & 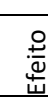 \\
\hline & Assoreamento de corpos de água & $\mathrm{s}$ & A & $\mathrm{R}$ & $\mathrm{ML} / \mathrm{T}$ & $\mathrm{RE}$ & PR & IN & $\mathrm{M}$ & $\mathrm{CM}$ \\
\hline & Poluição hídrica & $\mathrm{S}$ & A & $\mathrm{R}$ & $\mathrm{ML} / \mathrm{T}$ & $\mathrm{RE}$ & PR & IN & $\mathrm{M}$ & $\mathrm{CM}$ \\
\hline & Contaminação hídrica & MS & A & $\mathrm{R}$ & $\mathrm{ML} / \mathrm{T}$ & $\mathrm{RE}$ & PR & IN & $\mathrm{M}$ & $\mathrm{CM}$ \\
\hline Agricultura & Eutrofização das águas dos corpos hídricos superficiais & $\mathrm{S}$ & A & $\mathrm{R}$ & $\mathrm{ML} / \mathrm{T}$ & $\mathrm{RE}$ & PR & IN & $\mathrm{M}$ & $\mathrm{CM}$ \\
\hline & Mortandade de organismos aquáticos & $\mathrm{s}$ & A & $\mathrm{R}$ & $\mathrm{ML} / \mathrm{T}$ & RE & $\mathrm{D}$ & $\mathrm{IN}$ & $M$ & $\mathrm{CM}$ \\
\hline & Alteração na paisagem dos corpos hídricos & $\mathrm{S}$ & A & $\mathrm{L}$ & $\mathrm{ML} / \mathrm{T}$ & RE & $\mathrm{D}$ & IN & $\mathrm{M}$ & $\mathrm{CM}$ \\
\hline & Redução na disponibilidade dos recursos hídricos & MS & A & $\mathrm{R}$ & I/T & RE & $\mathrm{D}$ & $\mathrm{DI}$ & $\mathrm{M}$ & $\mathrm{CM}$ \\
\hline & Poluição hídrica & $\mathrm{S}$ & A & $\mathrm{R}$ & $\mathrm{ML} / \mathrm{T}$ & RE & PR & IN & $\mathrm{M}$ & $\mathrm{CM}$ \\
\hline Avicultura & Contaminação hídrica & MS & A & $\mathrm{R}$ & $\mathrm{ML} / \mathrm{T}$ & RE & PR & IN & $\mathrm{M}$ & $\mathrm{CM}$ \\
\hline Avicuicura & Eutrofização das águas dos corpos hídricos superficiais & MS & A & $\mathrm{R}$ & $\mathrm{ML} / \mathrm{T}$ & RE & PR & IN & $\mathrm{M}$ & $\mathrm{CM}$ \\
\hline & Alteração e degradação dos ambientes aquáticos & MS & A & $\mathrm{R}$ & $\mathrm{ML} / \mathrm{T}$ & RE & PR & IN & $\mathrm{M}$ & $\mathrm{CM}$ \\
\hline & Alteração do fluxo hídrico & $\mathrm{S}$ & A & $\mathrm{R}$ & $\mathrm{ML} / \mathrm{T}$ & RE & PR & IN & $\mathrm{M}$ & $\mathrm{CM}$ \\
\hline & Assoreamento de corpos de água & MS & A & $\mathrm{R}$ & $\mathrm{ML} / \mathrm{T}$ & $\mathrm{RE}$ & PR & IN & $\mathrm{M}$ & $\mathrm{CM}$ \\
\hline & Poluição hídrica & $\mathrm{S}$ & A & $\mathrm{R}$ & $\mathrm{ML} / \mathrm{T}$ & RE & PR & IN & $\mathrm{M}$ & $\mathrm{CM}$ \\
\hline Pecuária bovina extensiva & Contaminação hídrica & MS & A & $\mathrm{R}$ & $\mathrm{ML} / \mathrm{T}$ & RE & PR & IN & $\mathrm{M}$ & $\mathrm{CM}$ \\
\hline & Aumento na turbidez da água do Rio & $\mathrm{S}$ & A & $\mathrm{R}$ & $\mathrm{ML} / \mathrm{T}$ & $\mathrm{RE}$ & PR & IN & $\mathrm{M}$ & $\mathrm{CM}$ \\
\hline & Eutrofização das águas dos corpos hídricos superficiais & MS & A & $\mathrm{R}$ & $\mathrm{ML} / \mathrm{T}$ & $\mathrm{RE}$ & PR & IN & $\mathrm{M}$ & $\mathrm{CM}$ \\
\hline & Alteração da paisagem natural do rio & MS & A & $\mathrm{R}$ & $\mathrm{ML} / \mathrm{T}$ & $\mathrm{RE}$ & PR & IN & $\mathrm{M}$ & $\mathrm{CM}$ \\
\hline & Poluição hídrica & $\mathrm{S}$ & A & $\mathrm{R}$ & $\mathrm{ML} / \mathrm{T}$ & $\mathrm{RE}$ & PR & IN & $\mathrm{M}$ & $\mathrm{CM}$ \\
\hline & Contaminação hídrica & MS & A & $R$ & $\mathrm{ML} / \mathrm{T}$ & $\mathrm{RE}$ & $\mathrm{D}$ & $\mathrm{DI}$ & $\mathrm{M}$ & $\mathrm{CM}$ \\
\hline & Aumento da turbidez da água do rio & $\mathrm{S}$ & A & $R$ & $\mathrm{ML} / \mathrm{T}$ & $\mathrm{RE}$ & PR & IN & $\mathrm{M}$ & $\mathrm{CM}$ \\
\hline Suinocultura & Eutrofização do rio & $\mathrm{S}$ & A & $\mathrm{R}$ & $\mathrm{ML} / \mathrm{T}$ & $\mathrm{RE}$ & PR & IN & $M$ & $\mathrm{CM}$ \\
\hline & Aumento de odores desagradáveis & MS & A & $\mathrm{L}$ & $\mathrm{I} / \mathrm{T}$ & $\mathrm{RE}$ & $\mathrm{D}$ & IN & M & $\mathrm{CM}$ \\
\hline & Alteração da paisagem natural do rio & $\mathrm{S}$ & $\mathrm{A}$ & $\mathrm{R}$ & $\mathrm{ML} / \mathrm{T}$ & $\mathrm{RE}$ & $\mathrm{D}$ & IN & $\mathrm{M}$ & $\mathrm{CM}$ \\
\hline & Mortandade de organismos aquáticos & $\mathrm{S}$ & A & $\mathrm{R}$ & $\mathrm{ML} / \mathrm{T}$ & $\mathrm{RE}$ & $\mathrm{D}$ & $\mathrm{DI}$ & $\mathrm{M}$ & $\mathrm{CM}$ \\
\hline Cantarãnde áø & Alteração do fluxo hídrico & MS & $\mathrm{A}$ & $\mathrm{R}$ & $\mathrm{I} / \mathrm{T}$ & $\mathrm{RE}$ & $\mathrm{D}$ & IN & $\mathrm{M}$ & $\mathrm{CM}$ \\
\hline Captaçao de agua & Redução na disponibilidade de água nos corpos hídricos & MS & A & $\mathrm{E}$ & $\mathrm{ML} / \mathrm{T}$ & $\mathrm{RE}$ & $\mathrm{D}$ & IN & $\mathrm{M}$ & $\mathrm{CM}$ \\
\hline & Assoreamento de corpos de água & MS & $\mathrm{A}$ & $\mathrm{R}$ & $\mathrm{ML} / \mathrm{T}$ & $\mathrm{RE}$ & $\mathrm{D}$ & IN & $\mathrm{M}$ & $\mathrm{CM}$ \\
\hline & Poluição hídrica & MS & A & $\mathrm{R}$ & $\mathrm{ML} / \mathrm{T}$ & $\mathrm{RE}$ & PR & IN & $\mathrm{M}$ & $\mathrm{CM}$ \\
\hline Resmatamento & Contaminação hídrica & MS & A & $\mathrm{R}$ & $\mathrm{ML} / \mathrm{T}$ & $\mathrm{RE}$ & $\mathrm{D}$ & IN & $\mathrm{M}$ & $\mathrm{CM}$ \\
\hline Desmatamento & Alteração na qualidade das águas do rio & $\mathrm{S}$ & A & $\mathrm{R}$ & $\mathrm{ML} / \mathrm{T}$ & $\mathrm{RE}$ & $\mathrm{D}$ & IN & $\mathrm{M}$ & $\mathrm{CM}$ \\
\hline & Alteração e degradação dos ambientes aquáticos & $\mathrm{s}$ & A & $\mathrm{R}$ & $\mathrm{ML} / \mathrm{T}$ & $\mathrm{RE}$ & PR & IN & $\mathrm{M}$ & $\mathrm{CM}$ \\
\hline & Alteração da paisagem natural do rio & MS & A & $\mathrm{R}$ & $\mathrm{ML} / \mathrm{T}$ & $\mathrm{RE}$ & $\mathrm{D}$ & IN & $\mathrm{M}$ & $\mathrm{CM}$ \\
\hline & Poluição hídrica & $\mathrm{S}$ & A & $\mathrm{R}$ & $\mathrm{ML} / \mathrm{T}$ & $\mathrm{RE}$ & PR & IN & $\mathrm{M}$ & $\mathrm{CM}$ \\
\hline Ounii: & Contaminação hídrica & $\mathrm{S}$ & A & $\mathrm{R}$ & $\mathrm{ML} / \mathrm{T}$ & $\mathrm{RE}$ & PR & IN & $\mathrm{M}$ & $\mathrm{CM}$ \\
\hline Queijarla & Alteração na qualidade das águas do rio & $\mathrm{S}$ & A & $\mathrm{R}$ & $\mathrm{ML} / \mathrm{T}$ & $\mathrm{RE}$ & $\mathrm{D}$ & IN & $\mathrm{M}$ & $\mathrm{CM}$ \\
\hline & \begin{tabular}{|l|} 
Eutrofização do rio \\
\end{tabular} & $\mathrm{s}$ & A & $\mathrm{R}$ & $\mathrm{ML} / \mathrm{T}$ & $\mathrm{RE}$ & PR & IN & $\mathrm{M}$ & $\mathrm{CM}$ \\
\hline & Alteração do fluxo hídrico & MS & A & $\mathrm{R}$ & $\mathrm{ML} / \mathrm{T}$ & $\mathrm{RE}$ & $\mathrm{D}$ & $\mathrm{DI}$ & $\mathrm{M}$ & $\mathrm{CM}$ \\
\hline & Assoreamento de corpos de água & MS & A & $\mathrm{R}$ & $\mathrm{ML} / \mathrm{T}$ & $\mathrm{RE}$ & $\mathrm{D}$ & IN & $\mathrm{M}$ & $\mathrm{CM}$ \\
\hline & \begin{tabular}{|l|} 
Poluição hídrica \\
\end{tabular} & MS & A & $\mathrm{R}$ & $\mathrm{ML} / \mathrm{T}$ & $\mathrm{RE}$ & PR & IN & $\mathrm{M}$ & $\mathrm{CM}$ \\
\hline & Contaminação hídrica & MS & A & $\mathrm{R}$ & $\mathrm{ML} / \mathrm{T}$ & $\mathrm{RE}$ & PR & IN & $\mathrm{M}$ & $\mathrm{CM}$ \\
\hline & Eutrofização das águas do rio & MS & A & $\mathrm{R}$ & $\mathrm{ML} / \mathrm{T}$ & $\mathrm{RE}$ & PR & IN & $\mathrm{M}$ & $\mathrm{CM}$ \\
\hline Urbanızaçao & Alteração e degradação dos ambientes aquáticos & MS & A & $\mathrm{R}$ & $\mathrm{ML} / \mathrm{T}$ & $\mathrm{RE}$ & $\mathrm{D}$ & IN & $\mathrm{M}$ & $\mathrm{CM}$ \\
\hline & Aumento no volume demandado de água & MS & A & $\mathrm{R}$ & $\mathrm{ML} / \mathrm{T}$ & $\mathrm{RE}$ & $\mathrm{D}$ & $\mathrm{DI}$ & $\mathrm{M}$ & $\mathrm{CM}$ \\
\hline & Redução na disponibilidade de água & MS & A & $\mathrm{E}$ & $\mathrm{ML} / \mathrm{T}$ & $\mathrm{RE}$ & D & $\mathrm{DI}$ & M & $\mathrm{CM}$ \\
\hline & Aumento no desperdiço de água & MS & A & $\mathrm{R}$ & $\mathrm{ML} / \mathrm{T}$ & $\mathrm{RE}$ & $\mathrm{D}$ & IN & $\mathrm{M}$ & $\mathrm{CM}$ \\
\hline & Risco de escassez hídrica & MS & A & $E$ & $\mathrm{ML} / \mathrm{T}$ & $\mathrm{RE}$ & PR & IN & $\mathrm{M}$ & $\mathrm{CM}$ \\
\hline
\end{tabular}

Legenda: (B) Benéfico; (A) Adverso; (L) Local; (R) Regional; (E) Estratégico; (I) Imediato; (ML) Médio em Longo Prazo; (P) Permanente; (C) Cíclico; (T) Temporário; (RE) Reversível; (IR) Irreversível; (D) Determinístico; (PR) Probabilístico; (DI) Direto; (IN) Indireto; (M) Mitigável; (NM) Não-Mitigável; (CM) Cumulativo e (SI) Simples.

Na Figura 7, tem-se, em termos percentuais, a classificação dos impactos ambientais "muito 
significativos" e "significativos", confeccionada a partir das informações do Quadro 4.

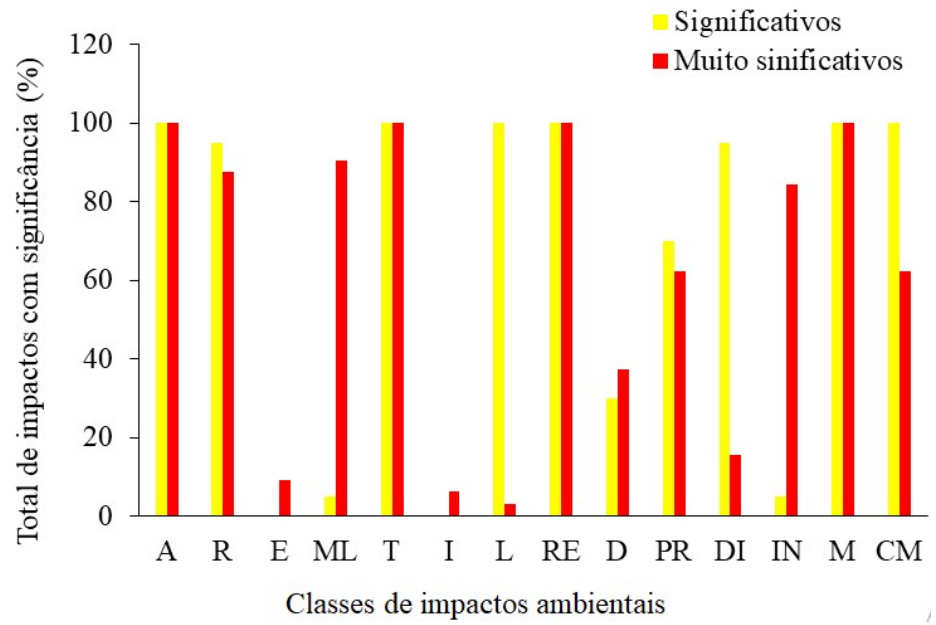

Figura 8: Classificação dos impactos ambientais "muito significativos" e "significativos". Legenda: (A) Adverso; (R) Regional; (E) Estratégico; (ML) Médio e Longo Prazo; (T) Temporário; (I) Imediato; (L) Local; (RE) Reversível; (D) Determinístico; (PR) Probabilístico; (DI) Direto; (IN) Indireto; (M) Mitigável e (CM) Cumulativo.

Na Figura 7, verifica-se que $100 \%$ dos impactos ambientais "muito significativos" e "significativos" são adversos. Em relação aos impactos "muitos significativos", 100\% são reversíveis. Além disso, vale destacar que todos os impactos ambientais significantes são 100\% mitigáveis. Diante disso, cabe ressaltar, que Ismael (2016) identificou os impactos ambientais do Rio Piancó do trecho do município de Coremas a Pombal, dentre os resultados obtidos ele constatou que todos os impactos ambientais significativos foram considerados adversos, temporários, reversíveis e mitigáveis. Diante desse contexto, é evidenciado que os impactos ambientais negativos para os componentes ambientais do Rio Piancó-Piranhas-Açu, em especial as suas águas, poderão ter os efeitos desses impactos sanados ou minimizados. Para isso, é de fundamental importância a aplicação de técnicas e mediadas de controle ambiental para alcançar o equilíbrio ecológico desse ecossistema.

Segundo Carvalho et al. (2019) para cada impacto negativo identificado, deverão ser propostas medidas e programas ambientais que visem sua mitigação, controle e/ou compensação. De forma contrária, os impactos positivos devem ser estimulados e ampliados. Portanto, são os programas ambientais que nortearão as ações desenvolvidas para proteger o meio ambiente e a comunidade dessas modificações, sendo essenciais nos Estudos de Impacto Ambiental (EIA) e para a manutenção da qualidade ambiental do ecossistema e da população afetados. Desse modo, as medidas de controle ambiental propostas para os impactos ambientais "significativos" e "muito significativos" estão expostas na Tabela 7.

Tabela 7: Medidas de controle ambiental para as águas do Rio Piancó-Piranhas-Açu

\begin{tabular}{ll}
\hline Impactos ambientais & Medidas de controle ambiental \\
\hline Assoreamento do leito do rio & $\begin{array}{l}\text { - Promover a recuperação da mata ciliar, pois ela barra a entrada de objetos e sedimentares no rio } \\
\text { e conserva o solo das margens, evitando erosões fluviais. }\end{array}$ \\
\hline Eutrofização das águas do rio & $\begin{array}{l}\text { - Tratar os efluentes domésticos e industriais por meio de um sistema de coleta e tratamento de } \\
\text { esgoto. Além disso, capacitar os agricultores e pecuaristas sobre o uso consciente de agrotóxicos } \\
\text { nas suas atividades. }\end{array}$ \\
\hline $\begin{array}{l}\text { Alteração e degradação de } \\
\text { ambientes aquáticos }\end{array}$ & $\begin{array}{l}\text { - Promover a recuperação da qualidade ambiental das águas do rio Piancó-Piranhas-Açu, por meio } \\
\text { do reflorestamento de sua mata ciliar. }\end{array}$ \\
\hline Poluição hídrica & $\begin{array}{l}\text { - Conscientizar os moradores da área de estudo sobre a importância de separar os resíduos sólidos } \\
\text { e não descartas em locais inapropriados, como as margens do rio. }\end{array}$ \\
\hline
\end{tabular}




\begin{tabular}{|c|c|}
\hline Contaminação hídrica & $\begin{array}{l}\text { - Conscientizar a população da área de estudo sobre a importância de não descarte o óleo de } \\
\text { cozinha usado no ralo. Além disso, alertar os agricultores e pecuaristas a respeito dos danos } \\
\text { ambientais que os agrotóxicos proporcionam ao meio ambiente, principalmente as águas dos rios. }\end{array}$ \\
\hline $\begin{array}{l}\text { Mortandade de organismos } \\
\text { aquáticos }\end{array}$ & - Utilizar pesticidas e fertilizantes orgânicos, para evitar a morte da fauna aquática do rio. \\
\hline Aumento de odores & $\begin{array}{l}\text { - Cessar o lançamento de esgotos brutos sem um pré-tratamento no corpo hídrico e promover a } \\
\text { desobstrução da calha do rio para regularizar o fluxo de escoamento natural do mesmo. }\end{array}$ \\
\hline Alteração do fluxo hídrico & $\begin{array}{l}\text { - Realizar a limpeza do leito do rio, retirando objetos e sedimentos depositados no fundo do } \\
\text { mesmo dificultando o fluxo natural. }\end{array}$ \\
\hline Alteração da paisagem do rio & $\begin{array}{l}\text { - Realizar o reflorestamento da mata ciliar do Rio Piancó-Piranhas-Açu, assim como a recuperação } \\
\text { dos demais componentes ambientais que proporcionam a vida de algumas espécies endêmicas } \\
\text { dessa localidade. }\end{array}$ \\
\hline $\begin{array}{l}\text { Aumento da Turbidez das } \\
\text { águas do rio }\end{array}$ & - Encerrar o lançamento de efluentes domésticos e industriais sem tratamento adequado. \\
\hline $\begin{array}{l}\text { Redução da disponibilidade } \\
\text { d'água e risco de escassez } \\
\text { hídrica }\end{array}$ & $\begin{array}{l}\text { - Realizar educação ambiental com os moradores da área de estudo e os da área urbana sobre o } \\
\text { uso racional e consciente dos recursos hídricos. }\end{array}$ \\
\hline
\end{tabular}

\section{CONCLUSÕES}

O georreferenciamento da área de estudo permitiu espacializar as informações e melhorar a qualidade e precisão da pesquisa, onde se constatou que partes das cidades de Pombal - PB e Paulista - PB estão inseridas dentro da APP do Rio Piancó-Piranhas-Açu. Além disso, verificou-se que a urbanização é a atividade antrópica que ocasionou o maior número de impactos ambientais "muito significativos" nas águas do rio, seguida da pecuária extensiva.

Vale ressaltar, que as atividades citadas anteriormente, juntamente com as demais que foram identificadas na área de influência do estudo, também ocasionam diversas alterações negativas em outros componentes ambientais, a exemplo do solo, do ar, da flora e fauna. Por fim, espera-se que os resultados obtidos deste estudo sirvam como base para estudos futuros nas águas do Rio Piancó-Piranhas-Açu. Além disso, espera-se que os órgãos públicos dos municípios elaborem políticas públicas para a área de estudo, especialmente para a Área de Preservação Permanente do rio da pesquisa.

\section{REFERÊNCIAS}

AZEVEDO, P. B.; LEITE, J. C. A.; OLIVEIRA, W. S. N.; SILVA, F. M.; FERREIRA, P. M. L.. Diagnóstico da degradação ambiental na área do lixão de Pombal - PB. Revista Verde de Agroecologia e Desenvolvimento Sustentável, v.10, n.1, p. 20-34, 2015. DOI: https://doi.org/10.18378/rvads.v10i1.3294

ANA. Agência Nacional de Águas. Panorama das águas no mundo. Brasília: Ana, 2018.

AESA. Agência de Gestão das Águas no Estado da Paraíba. Comitês de bacias Piranhas Açu. 2019.

BRASIL. Lei no 12.651. Institui o Novo Código Florestal Brasileiro. Brasília: DOU, 2012.

CBHPPA. Comitê da Bacia Hidrográfica do Rio PiancóPiranhas - Açu. A bacia. 2019.

CUNHA, B. C.; GUERRA, A. J. T.. Avaliação e perícia ambiental. 10 ed. Rio de Janeiro: Bertrand Brasil, 2010.

CPRM. Projeto cadastro de fontes de abastecimento por água subterrânea: diagnóstico do município de Paulista - PB.
Recife: Companhia de Pesquisa de Recursos Minerais, 2005.

CPRM. Projeto cadastro de fontes de abastecimento por água subterrânea: diagnóstico do município de Pombal - PB. Recife: Companhia de Pesquisa de Recursos Minerais, 2005.

CARVALHO, D. N.; BONIOLO, M. R.; SANTO, R. G.; BATISTA, L. V.; MALAVAZZI, A. A.; REIS, F. A. G. V.; GIORDANO, L. D. C.. Critérios usados na definição de áreas de influências, impactos e programas ambientais em estudos de impacto ambiental de usinas hidrelétricas brasileiras. Geociências, v. 37, n.3, p.639-653, 2019.

CONAMA. Conselho Nacional do Meio Ambiente. Resolução CONAMA no 001. Dispõe sobre procedimentos relativos ao Estudo de Impacto Ambiental e Relatório de Impacto ao Meio Ambiente. Brasília: DOU, 1986.

CUNHA, N. R. S.. A intensidade da exploração agropecuária como indicador da degradação ambiental na região dos Cerrados, Brasil. Revista de Economia e Sociologia Rural, v. 46, n. 2, p. 291-323, 2008

DNIT. Departamento Nacional de Infraestruturas de 
Transporte, 2009.

DNIT. Departamento Nacional de Infraestruturas de Transporte, 2009.

EAKIN, H. C.; LEMOS, M. C.; NELSON, D. R.. Differentiating capacities as a means to sustainable climate change adaptation. Global Environmental Change, v.27, p.1-8, 2014. DOI: https://doi.org/10.1016/j.gloenvcha.2014.04.013

FILHO, J. M. F.; GUIMARÃES, R.; CARVALHO, R. G. V. C.. Impactos ambientais em unidades de conservação urbanas: o caso da Área de Relevante Interesse Ecológico da llha da Coroa em Mossoró no Rio Grande do Norte, Brasil. Revista Brasileira de Geografia Física, v.10, n.1, p.304-316, 2017.

FERREIRA, C.. Análise socioambiental em propriedades rurais com nascentes em processo de recuperação no município de Lauro Muller - SC. Revista Ciência \& Cidadania, v.2, n.1, p. 92, 2016.

FOGLIATTI, M. C.; FILIPPO, S.; GOUDARD, B.. Avaliação de impactos ambientais: aplicação aos sistemas de transporte. Interciência, 2004.

FOGLIATTI, M. C.; FILIPPO, S.; GOUDARD, B.. Avaliação de impactos ambientais: aplicação aos sistemas de transporte. Interciência, 2004.

FRANCISCO, P. R. M.; PEREIRA, F. C.; BRANDÃO, Z. N.; ZONTA, J. H.; SANTOS, D.; SILVA, J.. Mapeamento da Aptidão Edáfica para Fruticultura Segundo o Zoneamento Agropecuário do Estado da Paraíba (Mapping of the edaphic suitability for fruit production). Revista Brasileira De Geografia Física, v.8, n.2, p.377-390, 2015.

IBGE. Instituto Brasileiro de Geografia e Estatística. Geociências: informações ambientais: tipos de solos. IBGE, 2010.

IBGE. Instituto Brasileiro de Geografia e Estatística. Banco de dados agregados: censo demográfico. IBGE, 2010.

ISMAEL, F. C. M.; LEITE, J. C. A.; ISMAEL, D. A. M.; SILVA, E. F.; FREITAS, G. P.; SOUSA, T. M. I.. Identificação de impactos ambientais nas águas do trecho perenizado do Rio Piancó. Revista em Agronegócio e Meio Ambiente, v.12, n.3, 9991017, 2019.

ISMAEL, F. C. M.. Avaliação de impactos ambientais nas águas do trecho perenizado do Rio Piancó e seus possíveis efeitos na produção agroindustrial primária local. Dissertação (Mestrado em Sistemas Agroindustriais) Universidade Federal de Campina Grande, Campina Grande, 2019.
JUNIOR, M. A. B. A.; ALMEIDA, R. S.; SILVA, G. O. C. Diagnóstico dos impactos ambientais provocados pelo lançamento de esgotos no rio Piancó em Pombal-PB. Revista Geociências, v.2, n.3, 2017.

MARTILDES, J. A. L.; FLORÊNCIO, P. R. C.; SILVA, A. F. L. R. A.; SILVA, R. A. F.; SILVA, E. M.; SANTOS, L. L.. Identificação e avaliação de impactos ambientais na fase de operação do Aterro Sanitário de Campina Grande-PB. Brazilian Journal of Development, v.6, n.3, p.13395-13415, 2020.

MARENGO, J. A.; ALVES, L. M.; SOARES, W. R.; RODRIGUEZ, D. A.; CAMARGO, H.; RIVEROS, M. P.; PABLÓ, A. D.. Two contrasting severe seasonal extremes in tropical South America in 2012: flood. Amazonia and drought in northeast Brazil. Journal of climate, v.26, n.22, p.9137-9154, 2013. DOI: https://doi.org/10.1175/JCLI-D-12-00642.1

MMA. Ministério do Meio Ambiente. Água: um recurso cada vez mais ameaçado. Brasília, 2016.

PHILIPPI, J. A.; ROMERO, M. A.; BRUNA, G. C.. Curso de gestão ambiental, 2004.

INTO, F.; ANTUNES, S. C.. Biomanipulação para o controlo da eutrofização. Revista de Ciência Elementar, v.8, n.1, 2020. DOI: http://doi.org/10.24927/rce2020.010.

RAMOS, G. G.; ALVES, J. B.; RAÚJO, M. D. F.; FERREIRA, V. S. G.; PINTO, M. G. C.; LEITE, M. J. H.; RIBEIRO, I. R. Levantamento dos impactos ambientais de um trecho de mata ciliar em região de Caatinga no sertão paraibano. Brazilian Journal of Development, v.6, n.7, p.52848-52859, 2020.

SÁNCHEZ, L. E.. Avaliação de impacto ambiental: conceitos e métodos. Oficina de Textos, p.200-212, 2008.

SÁ, G. B.. Avaliação dos impactos ambientais resultantes da gestão do saneamento básico na cidade de Pombal - PB. Monografia - (Graduação em Engenharia ambiental) Universidade Federal de Campina Grande, Pombal/PB, 2016.

SILVA, T. G. N.; GAMA, R. C.; TEIXEIRA, L. G.; SANTOS, G. R.; SOUSA, R. M.; SOUZA, P. B.. Diagnóstico ambiental de uma área de proteção permanente (app), Formoso do AraguaiaTO. Revista da Universidade Vale do Rio Verde, v.16, n.2, 2018.

SOUZA, W. B.; MELO, L. P.; LIMA, L. C. S.; SOUZA, D. C.; TEXEIRA, T. T.. Mapeamento e avaliação da potabilidade de água proveniente de fontes alternativas de captação na cidade de Astolfo Dutra. Águas Subterrâneas, v.32, n.3, 2018. DOI: https://doi.org/10.14295/ras.v32i3.29179

A CBPC - Companhia Brasileira de Produção Científica (CNPJ: 11.221.422/0001-03) detém os direitos materiais desta publicação. Os direitos referem-se à publicação do trabalho em qualquer parte do mundo, incluindo os direitos às renovações, expansões e disseminações da contribuição, bem como outros direitos subsidiários. Todos os trabalhos publicados eletronicamente poderão posteriormente ser publicados em coletâneas impressas sob coordenação da Sustenere Publishing, da Companhia Brasileira de Produção Científica e seus parceiros autorizados. Os (as) autores (as) preservam os direitos autorais, mas não têm permissão para a publicação da contribuição em outro meio, impresso ou digital, em português ou em tradução. 